\title{
Choice Sets, Gender, and Candidate Choice in Brazil
}

\author{
Rosario Aguilar $\quad$ Saul Cunow ${ }^{\mathrm{b}} \quad$ Scott Desposato $^{\mathrm{c}}$
}

January 20, 2015

\begin{abstract}
Is there a gender gap in Latin American attitudes toward women politicians? While scholars of Latin America have examined the role of institutions and quotas in women's electoral success, less attention has been paid to voters' attitudes about women leaders. In this paper, we report on two survey experiments and an observational study in Brazil looking at the effect of candidate gender on vote choice. We asked subjects to chose a candidate from a hypothetical ballot while randomly varying candidates' gender. We find a strong and consistent 5-7 percentage point pro-female bias. Our experiments illustrate a novel approach to testing candidate choice models.
\end{abstract}

Keywords: experiments, elections, women's representation; candidate gender; candidate race; electoral institutions; Latin America; Brazil

${ }^{a}$ Centro de Investigación y Docencia Económicas,Carretera México-Toluca 3655 Col. Lomas de Santa Fe, Delegación Álvaro Obregón, C.P. 01210, México, D.F., Mexico, rosario.aguilar@cide.edu

${ }^{\mathrm{b}}$ Department of Political Science, University of California, San Diego, 9500 Gilman Drive MC 0521, La Jolla, CA 92093-0521, scunow@ucsd.edu

${ }^{\mathrm{c} C o r r e s p o n d i n g ~ A u t h o r, ~ I n s t i t u t ~ f u ̈ r ~ P o l i t i k w i s s e n s c h a f t, ~ U n i v e r s i t a ̈ t ~ Z u ̈ r i c h, ~ A f f o l t e r n s t r a s s e ~} 56,8050$ Zürich Tel: 04463438 41, and Department of Political Science, University of California, San Diego, 9500 Gilman Drive MC 0521, La Jolla, CA 92093-0521 (858) 534-3548 


\section{Introduction}

Recent presidential elections suggest that a transformation in gender politics is taking place in Latin America, with women running for - and often winning - the presidency across the region. Today, Brazil, Chile, and Argentina all have women presidents. In the past, Ecuador, Bolivia, Costa Rica, and Nicaragua have also had women leaders. In other countries, women are competing at the highest level, suggesting more changes in the future. The incumbent party (PAN) in Mexico nominated a woman candidate in the last election. In Chile, both front-runners in 2013-2014 cycle were women. In Peru, Keiko Fujimori nearly defeated Ollanta Humala in 2011. The success of women at the highest levels suggests that Latin America has made great strides in gender equality and has surpassed many developed countries, including the United States.

However, there remain many troubling signs of inequality. On most social indicators, women still struggle with less access to education, lower incomes, and lower rates of labor force participation. Attitudes among many Latin Americans are still very traditional and conservative, with many in public opinion surveys supporting the notion that "women's place is in the home". Even more stunning, more than a quarter of Brazilians in a recent study agreed that women who dress and act provocatively "deserve to be attacked and raped"(IPEA, 2014). In the political sphere, there remains a contrast between the success of women seeking national office, and their struggles in lower level competitions. While women have made progress in Presidential elections, in most countries they continue to lag behind men in legislative and local elections.

Most research focused on Latin America's female politicians has analyzed the effectiveness of quotas systems in helping women access elected positions (Baldez, 2004; Franceschet, Krook and Piscopo, 2012; Htun and Jones, 2002; Jones, 1996, 1998, 2004, 2009; Jones and Navia, 1999; Schmidt and Saunders, 2004). Conclusions from that literature focus on the best institutions to bring about gender parity in representation. Yet legal prescriptions and descriptive representation may be no substitute for deeper structural and social changes. For 
example, while Brazil requires that $30 \%$ of list candidates be women, only $10 \%$ of deputies elected in 2014 were women. ${ }^{1}$ In addition, without attitudinal changes among voters, women will always face additional challenges in their political advancement. Understanding the gender gap in descriptive representation requires moving beyond institutions to also examine attitudes, yet the literature on attitudes and gender is largely limited to developed democracies (Dolan, 1997, 2010; Terkildsen, 1993; Lammers, Gordijn and Otten, 2009; McElroy and Marsh, 2010; Philpot and Walton Jr, 2007; Sanbonmatsu, 2002).

In this paper we investigate gender bias in candidate choice in Brazil, using two experiments and an observational study of election results. The two survey experiments measure gender bias in candidate choice. In each, we ask subjects to choose a preferred candidate from a list of hypothetical candidates for legislative office. In the first experiment we manipulated the race and gender of three candidates on a hypothetical ballot. We find a significant bias towards female candidates when comparing white male and female candidates, but the effect is much smaller when comparing male and female black candidates. In the second experiment, we focus on white candidates and vary ballot size from 3 to 12, using Cunow's (2014) MPH software. We test for differences in expressed support as a function of candidate gender. We find a strong and remarkably consistent 7 percentage point bias in favor of women candidates. This pro-woman bias is remarkably consistent across subjects' gender, education, political interest, and issue preferences. There is a slight difference in effect size across party: the pro-female bias was strongest for subjects supporting leftist parties, but even so, there is pro-female bias for subjects supporting other parties, as well as among independent subjects.

Our experimental results have several possible interpretations. One is a demonstration

\footnotetext{
${ }^{1}$ The quota law is quite lax. If there are more than $70 \%$ of candidates of the same sex on a party list, candidates of the over-represented gender can be removed from the list but they are not substituted by candidates of the under-represented gender. Furthermore, this policy only applies if parties submit the maximum number of candidates possible per constituency. This maximum was raised from $100 \%$ to $150 \%$ of total seats per constituency at the time the quota law passed, thus minimizing the effect of the quota law. Finally, because of Brazil's open list system, the law does not include restrictions for the position of female candidates on party lists.
} 
effect associated with the election of the then very popular Dilma Rousseff, Brazil's first woman president, where positive affect for the President might benefit all female candidates. We use a regression discontinuity design (RDD) to test for demonstration effects in mayoral elections, asking whether the election of a female mayor has positive effects for women running for other offices in subsequent elections. Results in this case are negative; the election of a woman mayor reduces expected vote share for women in some downstream elections; in others, the demonstration effect has no obvious effect.

We proceed in four additional steps. In section two, we discuss the literature on gender stereotypes affecting vote choice. The third section describes our experimental design. The fourth section presents the results from the experiments as well as the regression discontinuity. The final section discusses our findings and suggests directions for future research.

\section{Factors Affecting Support for Female Politicians}

As mentioned, most previous work on Latin America focuses on quotas' and other rules' impact on descriptive representation - the number of women elected under various institutional frameworks. Research on voters' attitudes about gender, however, is less common in Latin America. The majority of the studies looking at women's political participation in

electoral politics examine established democracies, usually the United States, Canada, and Western Europe. Previous work on voters, primarily survey research, examines the impact of individual traits, broader context, and stereotypes in shaping voter attitudes toward female politicians.

Scholars have found many individual traits that affect attitudes toward female candidates, including gender of subject, political interest, age, education, and ideology (Dolan, 1997; Sanbonmatsu, 2002). At the same time, these do not appear to have universal traction cross-nationally. Schwindt-Bayer, Malecki and Crisp (2010) looked at three cases with single transferable vote and found that voters preferred female candidates in Australia, male can- 
didates in Ireland, and were indifferent across candidate gender in Malta, with some factors flipping signs or losing significance across cases. This suggests that gender attitudes are highly context and culture specific.

Beyond individual factors, scholars also argue that context matters. Much of this literature focuses on the role of development. Inglehart and Norris (2003) argue that modernization leads citizens to hold more egalitarian views regarding gender. On the other hand, there are notable deviant cases where gaps in women's political representation persist in developed countries, like the United States and Japan.

In addition to modernization, scholars have also examined the impact of other contextual factors on gender attitudes, including socialization, status discontent, and elite cues. Morgan and Buice (2013) examine both contextual and individual factors that affect attitudes toward women, as well as their interaction. Status discontent suggests that men will be threatened by increasing female representation, but only above a certain threshold. Elite cues also have differential effects because they should only affect those with weaker opinions. Morgan and Buice (2013) find no evidence of any socialization interactions, but they do find evidence of status discontent and elite cue impacts on gender attitudes.

Citizens' attitudes toward female politicians can also be mediated by stereotypes and group consciousness. The majority of studies looking at the effect of stereotypes and group consciousness on voters' attitudes toward female candidates are based in the U.S. and find a negative effect of gender stereotypes, affecting mostly male voters, on female candidates' electoral success. For example, people perceive women as soft, caring, nurturing, and compassionate, while they perceive men as good leaders, strong, and decisive, thereby making men more appealing for decision-making positions (Alexander and Andersen, 1993; Burrell, 1995; Huddy and Terkildsen, 1993; Kahn and Fridkin, 1996; Koch, 1999; Lawless, 2004). Thus, voters often consider men to be better suited for the demands of political office. In addition, when voters face female candidates, their electoral decisions are mediated by stereotypes related to women's competence in dealing with typically male issues. Those voters who 
think that women can deal with "male issues" tend to be more supportive of female candidates (Dolan, 2010; Lammers, Gordijn and Otten, 2009). Some studies have also shown the importance of voters' perceptions of the most important problem facing their country when deciding between a female and a male candidate. In situations where voters think that social issues (e.g. health care) are the most relevant, they tend to favor women over men; but when voters think the main problem is more competitive in nature (e.g. war, economy, etc.) they tend to favor men over women (Lammers, Gordijn and Otten, 2009).

Brazil provides a difficult and contradictory case for this literature. On the one hand, Brazil appears to be a progressive case where female politicians can compete. The current President is a woman, and in surveys, Brazilians report that they see female politicians as more honest, responsible, and capable than men (Htun, 2002). On the other hand, in the legislature, even with quota laws, women hold less than $10 \%$ of the seats (IPU, 2014). Scholars described Brazilian politics as "dominated by masculine personality cult" in which there have not been many women in positions of power (Htun, 2002, 472) and where women lose to men in within-party competition (Htun and Jones, 2002).

We seek to contribute in two ways. First, we use experimental and regression discontinuity analysis to eliminate confounding and provide better measures of the impact of gender on voter support for candidates. Previous work on Brazil is largely observational - examining aggregate electoral returns or survey data. But while such data can be instructive, there are two major challenges to measuring the independent effect of candidate gender on vote choice. One is that no two candidates are alike, differing in policy positions, campaign strategies, charisma, experience, and anything else that matters, and it would be impossible to anticipate and account for every factor that matters. The other is that candidates may emerge strategically - one might expect female candidates to emerge in the most promising contexts for female candidates. Both mean that we are unlikely to accurately measure the impact of candidate gender on vote choice using observational data.

Second, we propose and test an explanation for the difference in women's success at the 
legislative and presidential levels. In an earlier study on race, we found that voters' attitudes interact with institutions in shaping their candidate selection. When voters were choosing between just three leading candidates, they were more likely to choose the candidate that best matched their preferences. But when choice sets were large - say 12 or more candidates - voters were overwhelmed by the task of sorting and choosing, and instead fell back on latent racial biases - with white subjects choosing white candidates, and nonwhite subjects choosing nonwhite candidates (Aguilar et al., Forthcoming). The explanation is that voters have latent racial biases that are only visible when they have difficulty making decisions.

We imagine a similar mechanism at work in Brazil. In most recent Presidential campaigns there have been just two competitive candidates. Thus, when voting for President, voters should evaluate candidates carefully and without any latent bias. In contrast, Brazil uses a highly permissive electoral system for legislative elections, resulting in hundreds of candidates in each district ${ }^{2}$. In this environment, where voters are overwhelmed with large choice sets, careful policy analysis of all candidates is impossible. Instead, voters should use other heuristics, including gender, to choose candidates. We expect these heuristics to favor male over female candidates. This leads us to our two core hypotheses:

Hypothesis 1 We expect a negative gender gap in candidate preference; all else equal, male candidates will have more expressed support than female candidates.

In addition, we test for the impact of subjects' characteristics on these attitudes. We examine the impact of subject gender, education, political interest, policy priorities, and ideology, as well as interactions between subject gender and these factors.

The second core hypothesis addresses the puzzle of differential performance across levels - why women are winning the presidency, but losing in legislative elections:

Hypothesis 2 The size of the gender gap will vary with ballot length; it will be small when voters choose between only a few candidates, but will grow as choice sets become large and

\footnotetext{
${ }^{2}$ City council, state assembly, and national lower house elections all use open-list proportional representation. For the national and state elections, states act as electoral districts. In most states there are hundreds of candidates, and almost 1,000 compete in the largest states. See Cunow (2014) for more details.
} 
complicated. When choosing between many candidates - as in a proportional representation ballot - voters' will rely less on a careful analysis of policy positions and will instead fall back on latent gender biases, reducing vote shares for women.

In the next section, we describe our experiments, then turn to results.

\section{Experimental Design}

We used two survey experiments to test for gender bias in attitudes. We conducted the first in São Paulo, Brazil from June to August, 2011. A total of approximately 600 adults participated. Survey respondents were presented with profiles of hypothetical candidates, were told that these might run for federal deputy in the next elections, and were asked who they would vote for or if they would prefer to abstain. Candidate profiles included candidates' names, photos, brief biographies, and policy positions on three issues. Subjects were also asked a set of questions about their own income, education, political interest, party affiliation, and race. Subjects were sampled in a diverse set of neighborhoods across São Paulo and surveys were conducted in person in public places including sidewalks, parks, and plazas.

The key treatment was the random assignment of candidate gender and race. Respondents were randomly assigned to one of four experimental conditions. In each condition, respondents were presented with profiles of three hypothetical candidates. Across all conditions, the profiles of two of the candidates (Sérgio and Leonardo) remained constant while the profile of the third candidate (Fernando), henceforth referred to as "the treatment candidate", was varied to show a white male, white female, black male, or a black female.

\section{FIGURE 1 ABOUT HERE}

Figure 1 shows the four sets of candidate profiles used in the experiment. ${ }^{3}$ Across treat-

\footnotetext{
${ }^{3}$ We also varied ballot order such that the treatment candidate was not always in the middle position on the ballot
} 
ment conditions, the only differences in the candidate profiles are the photo of the treatment candidate and some information in the profile that was changed to reflect the candidate's gender such as the candidate's name (Fernando became Fernanda) and the gender of the candidate's spouse, as well as some grammatical changes (e.g. changing "him" to "her" and using the female version of adjectives).

We estimate the effect of candidate race and gender by comparing the vote share of the treatment candidate across experimental conditions. Given that respondents were randomly assigned to the four experimental conditions and assuming that (as we illustrate below) our randomization was successful, the subject profiles in each of the four experimental conditions were equivalent. The only differences across conditions were the race and gender of Fernando/Fernanda. We would expect then, that if the race and gender of candidates does not influence vote choice, support for Fernando/Fernanda candidates would have been equal in all four experimental conditions. Similarly, any differences in the percentage of subjects preferring the treatment candidate across conditions can be attributed to a preference among subjects in the experiment for candidates of a particular race and gender as there is no other variation that could explain those differences.

Given our limited sample size, we followed up the first study with a second survey experiment conducted between June and August, 2013. In this experiment we surveyed a nationwide sample of 4,000 Brazilian voters who were recruited from a large panel maintained by a private market research firm. Respondents were informed that they would be participating in an academic study about political attitudes and were compensated with points that could be redeemed to purchase items from the survey firm's online marketplace. The procedure in this experiment is similar to the first: respondents answer some questions about themselves, view a ballot with candidate profiles, and choose a preferred candidate. A key difference with the first experiment however, is the use of a new online survey platform, MPH, to implement the survey (Cunow, 2014).

The MPH platform has a number of features that are useful for researchers conducting 
survey experiments. Most importantly for our purposes, it fully randomizes the candidate profile generation process. The process works as follows. For each respondent, MPH constructs a new ballot from a pool of researcher-generated candidate attributes. We supplied the software with 36 candidate names, biographies, photographs, and policy positions. After randomly assigning respondents to view a 3, 6, or 12 candidate ballot, MPH creates a new ballot for each respondent. The ballot is generated by randomly drawing without replacement from the pool of candidate attributes and assigning to each ballot position a name, biography, photograph, and set of policy positions. This process is repeated until the ballot is complete. Figure 2 presents sample 3, 6, and 12 candidate ballots.

Regardless of the number of candidates on the ballot, the proportions of white male, black male and white female candidates are maintained constant at $1 / 3$. The candidate attributes we supplied had equivalent male and female versions which only varied in their names (e.g. Marcelo and Marcela), the gender of their spouses, and the grammar used in the profiles. As a result, for each male candidate there was an equivalent female. As in our first experiment we estimate the effect of candidate gender on vote choice by comparing the aggregate vote shares of the female and male candidates in the experiment. Unlike our first experiment however, there is no control group. Rather, because all of the candidate attributes are orthogonal to one another, in the aggregate all of the male and female candidates in the experiment should otherwise be equivalent and any differences in their vote shares can be attributed to their race and gender. This approach is similar to conjoint analysis, a technique often used in marketing but also recently applied in work in political science (Hainmueller, Hopkins and Yamamoto, 2014; Cunow, 2014).

\section{FIGURE 2 ABOUT HERE}

Fully randomizing the generation of the candidate profiles has a number of important advantages over the "static" approach we employed in our first experiment with in-person interviews. By drawing from a larger pool of candidate attributes, we can more confidently attribute any treatment effects to candidate gender rather than to the names or photographs 
used in the experiment. In other words, since we sample from 12 photos, names and biographies of female candidates, it is less likely that any observed gender effects will will be driven by the particular photos, names, or biographies being used (e.g. if the photo of the female candidate used in the experiment is somehow more trustworthy than that of her male equivalent for the control group). Similarly, we also avoid potentially undetectable interaction effects whereby gender effects might only appear when certain other candidate attributes are present (e.g. if voters only prefer female candidate over male candidates when the candidates' backgrounds include degrees in economics). For a more detailed discussion of the MPH platform and its benefits see Cunow (2014). ${ }^{4}$

\section{Results}

Our initial experiment offered subjects a choice between three candidates. Two candidates' pictures and profiles never varied and the third candidate was the treatment candidate. For the treatment candidate, the policy position and profile never varied, but the picture varied between male and female candidates and names and pronouns were changed to correspond accordingly (Fernando or Fernanda; "his" or "hers").

The appropriate comparison is thus the percentage of subjects voting for the treatment candidate when that candidate was a woman ("Fernanda") versus the percentage voting for the treatment candidate when assigned gender was male ("Fernando"). Table 1 shows the percentage of subjects in each treatment that chose "Fernando/a", the treatment candidate. For both white and black candidates, there is a positive gender gap, with a higher proportion of subjects preferring a female Fernanda over a male equivalent. Overall, $26 \%$ of subjects chose a female Fernanda, while $20 \%$ chose a male "Fernando" (p-value for difference .07). When partitioned by candidate race, there is additional variance. The effect is larger, and significant for the white candidates: a 10\% difference, versus a small and insignificant result for subjects that saw a black Fernando or Fernanda. Subjects also did not particularly like

\footnotetext{
${ }^{4}$ Paper available at: http://acsweb.ucsd.edu/ scunow/
} 
any of our Fernando/Fernanda's, as the percentage choosing that candidate was consistently less than $33 \% .^{5}$

As one follow-up, we examined subjects' perceptions of the treatment candidate, that is, the candidate whose gender was varied, as a function of candidate gender. At the end of the treatment, we asked subjects about their perceptions of candidate traits, including competence and honesty. We tested whether subject perceptions of the hypothetical candidate varied with candidate gender (not shown). Differences in perceptions of candidate quality did not vary significantly with candidate gender.

In the second experiment, we focused on the impact of ballot structure on choice psychology. Tables 2 through 6 report cross tabs of vote choice and related treatments. In each of these tables, the cell figures are the proportion of subjects that voted for a female candidate. In every experimental treatment, exactly one-third of candidates were women ( 1 of 3,2 of 6 , or 4 of 12). Thus, if gender had no impact on Brazilian voters' attitudes, we should consistently see .33 of subjects choosing a female candidate. Bias against women politicians would be indicated by values below .33; bias in favor of women by figures above .33.

Table 2 addresses our core hypothesis regarding gender and choice set size. For both men and women, there is a consistent pro-female bias in candidate choice. Overall, $40 \%$ of subjects chose a female candidate across all treatments; this figure is significantly greater than the baseline $33 \%$ of gender-blind voting. For men, there is no evidence of any sensitivity to choice set size; the pro-female bias is quite stable across all ballot treatments. Support for female candidates by men is $37 \%$ for 3 -candidate ballots, $40 \%$ for 6 candidate ballots, and $41 \%$ for 12 candidate ballots. There are are no significant differences across ballot lengths for men, suggesting no latent preferences that are revealed only in larger choice sets.

For women, the pattern is similar, with suggestive, but not significant differences across

\footnotetext{
${ }^{5}$ This may have been because our candidate was a centrist relative to the other competing candidates, or because one of the other candidates was more attractive for some other reason. We did control for ballot order by randomly varying ballot position by many different ballot orderings and randomly assigning the ordering to each subject.
} 
ballot length. For both 3 and 6-candidate ballots, women subjects have a steady pro-female bias in behavior, similar to that of male subjects. Their support for women candidates falls to $38 \%$ for the twelve candidate ballot. Given the relatively small sample size for that treatment, however, the results are not significant and the trend could easily be explained by sampling variance. Thus we find that both women and men express a stable pro-female bias that does not vary with ballot length.

We also examined whether there were any patterns in support across other standard covariates. The short answer is that the pro-female bias is remarkably stable across all controls, and remains stable in our multivariate analysis (below).

Table 3 shows support for female candidates by gender and education level. Given previous work on gender in Latin America, with findings that voters in lower education cohorts maintain traditional gender role support, we expected such a trend to emerge in our experiment. The table shows, however, that the experiment does not provide evidence of an education - gender voting relationship. As observed previously, the patterns across education levels and across subject gender are remarkably stable, with female candidate voting consistently near $40 \%$. An important shortcoming for this study, however, is the severe under-representation of low-education subjects, with only about 200 subjects having less than a high school education.

Table 4 compares the magnitude of the gender gap as a function of self-reported political interest. Again, we find no difference in the gender gap across levels of political interest. There is again a consistent 7 percentage point positive gender gap across all levels of political interest, with very little variance.

Previous work has also found that female candidates do best when focusing on "women's issues", as women candidates enjoy or suffer a form of issue ownership and credibility in these areas, including family issues, and many social welfare issues. Table 5 shows voting by subject and candidate issues. The first part of the table shows female candidate support by subjects' top-ranked issue. Note that while subjects could choose between 12 issues, more 
than half identified corruption as the top issue, and $83 \%$ of respondents chose either corruption, education, or healthcare. The observed differences in voting for women candidates are consistent with previous work on gender. Subjects whose top issues are traditionally male dominated have weaker preferences for women candidates. For those most concerned with crime, the economy, or corruption, $39 \%$ chose women candidates. Similarly, subjects whose top issues were those traditionally dominated by women - education and healthcare - have slightly stronger preferences for female candidates: $43 \%$ and $42 \%$, respectively.

While this variation across issues appears to explain part of the pro-woman bias in behavior, for every issue category, there is a positive gender gap, as the preference for women candidates is always above the null rate of .33. For most issues these positive gender gaps are significant. They are not significant for crime or the economy, but fewer than 200 subjects ranked those issues first. Furthermore, while the trends are suggestive and consistent with the literature, the cross-issue differences are not statistically significant.

Table 6 shows female candidate support by age cohort and by gender. Again, all age cohorts show a roughly 7 percentage point pro-female candidate bias, consistently favoring women candidates more frequently than expected under gender-blind voting. For women, support for female candidates is quite steady across all age groups. For men, the pro-female trend increases gradually with age, but again, the trend is not statistically significant. These results contrast with previous research on the United States, which found that older men were less likely to support a female candidate than younger men and than older women (Flannelly, 2002).

The stability and strength of the pro-woman bias is surprising. One potential confounding variable is partisanship. Perhaps, one might suggest, gender is a cue for ideology or policy positions. ${ }^{6}$ In many countries, women politicians tend to be members of left-of-center parties, or to take left-of-center policy positions. Of course there are many exceptions, but gender might signal to subjects the ideological tendency of the candidate. This tendency should

\footnotetext{
${ }^{6}$ Thanks to Randy Stevenson for this suggestion.
} 
be exacerbated by our research design, in which candidates' party identification was not provided.

An implication is that subjects affiliated with leftist parties might be using gender as a cue, and thus selecting women at higher rates than nonpartisans and center/right subjects. In other words, perhaps there is no gender bias, instead, gender is an informational shortcut for ideology. We test this possibility in Table 7. Note first that few of our subjects expressed a partisan preference. $81 \%$ simply responded that they had no party preference or partisanship. Just 18\% expressed any partisanship, a total of 698 subjects. These "partisans" expressed preferences for 27 distinct political parties. Most parties were preferred by fewer than 10 subjects. Just three had more than 50: the ruling Worker's Party, or PT; the previous ruling party, the PSDB; and the Green Party, or PV. Note that $1 \%$ of respondents responded affirmatively to the question of partisanship, but failed to identify which party they preferred. Some of these identified more than one party or a class of parties ("The PT and the PCdoB", or "All authentic leftist parties"). Other respondents in this category identified an individual politician instead of a party ("Dilma" (the current president), "Maluf", or "Eduardo Suplicy", for example).

The table shows that there is increased gender voting among affiliates of the leftist Workers' Party (PT), the Green Party (PV), and the combination of all other small parties. Fully half of Green Party members selected a female candidate, significantly more than the baseline one-third of the null hypothesis. For the Worker's Party (PT), 44\% selected a female candidate, also significantly different from the baseline .33. Subjects in the "Other" category also chose the female canddiates at higher rates. In contrast, in the largest non-leftist party, the PSDB, the gender gap in candidate choice was lower (37\%), but still greater than the baseline .33 (though not significantly so).

The results are suggestive of a difference between leftist and non-leftist parties, but those differences are not significant. And again, the consistent pro-female bias in candidate choice emerges for every category. These results might, of course, be different with a larger sample, 
and the analysis is made difficult by relatively low rates of partisanship among our subjects in particular, and Brazilians in general. However, the conclusion from this analysis is that while partisanship may affect pro-women voting, and leftist parties appear to have higher positive gender gaps, these results are merely suggestive. Even after controlling for partisanship, there are still significant pro-women biases in candidate choice.

We now assess the impact of these variables jointly in a multivariate model. In this case, we consider the causal effect of candidate gender when controlling for multiple covariates in a multivariate model. Recall that each voter faces a multinomial choice problem; each sees a set of 3,6 , or 12 candidates, and must choose one. There are potentially relevant characteristics of both voters and candidates that we would expect to be considered.

Because each subject is choosing between several alternatives, and because the key treatments vary across the alternatives, we estimate a conditional logit model to determine the effect of gender on candidate choice while controlling for other variables.

Table 8 shows the results of our mixed logit models. The critical covariates and their estimates are shown in the first several rows of the table. In Model 1, Woman Candidate, is interacted with ballot length; in Models 2 and 3, Woman Candidate enters the models without interactions. In all models, with controls, there is a steady and consistent pro-female bias in candidate choice. For Model 1, there is no evidence of a ballot length-candidate choice interaction; the coefficients are not significantly different from each other (test not shown). In Model 2, Woman candidate also enters as a main effect and as an interaction with Subject Gender (Woman $=1$ ). Those results again show a strong pro-female bias in candidate choice, but no difference between men and women, as the interaction between Woman Candidate and Woman Subject is not significant. Our dummy variable for subject partisanship, as in the simple bivariate analysis, does not add explanatory power. Model 3 adds interactions between Woman Candidate and key issue areas; again with no significant interactions. ${ }^{7}$

Covariates reveal other patterns affecting vote choice. Ballot position does affect results;

\footnotetext{
${ }^{7}$ We conducted a likelihood ratio test for the joint significance of the policy and partisanship interactions with gender and failed to reject the null of no significant impact on the model.
} 
subjects are more likely to choose candidates near the top of the ballot than those further down. Candidates' proximity to voters, as measured by their policy rank, is also significant. Candidates whose positions are more consistent with those of voters are significantly more likely to be chosen. This result is reassuring both for our understandings of Brazilian democracy, as well as for our assessments of how seriously subjects took the exercise of the experiment. Finally, there is also a pro-black bias in candidate support. Nonwhite candidates receive significantly higher support than white candidates. Our interaction between nonwhite candidate and nonwhite subject shows that the pro-black bias is much stronger for nonwhite subjects. These results are consistent with our earlier work on race and voting in Brazil (Aguilar et al., Forthcoming).

\section{The "Demonstration Effect" of Women in Office}

How can we explain the strong preference for female candidates we observe in our experiments? One possibility is that voters preferred the female candidates in the experiments because of recent positive experiences with a female president. In 2010, Brazilians elected the first female president in the country's history, Dilma Rousseff. We conducted our first experiment approximately six months after Dilma's inauguration and near the height of her popularity. ${ }^{8}$ It is possible that having an ongoing positive experience with a woman elected to the most visible and powerful office in the country led many Brazilian voters to prefer female candidates for other offices, including those in our survey. This is what we refer to as the "demonstration effect" - a recent or ongoing experience with a member of a previously underrepresented group may demonstrate to voters the suitability of members of that group for leadership and lead voters to prefer such candidate types in subsequent elections.

We test this hypothesis by analyzing whether the election of a female mayor and the experience of a woman running local government in a municipality increases voteshare for

\footnotetext{
${ }^{8}$ Our second experiment was conducted during a wave of mass protests in 2013 when Dilma's approval ratings were considerably lower. She has since been reelected.
} 
female candidates in subsequent elections. ${ }^{9}$ We employ a regression discontinuity design (RDD) to test for a demonstration effect of female mayors elected in 2008 on the municipal vote share of female candidates in the subsequent 2010 national elections in Brazil. We hypothesize that the experience of living in a municipality where the local government is run by a female mayor will increase the vote share of female candidates in the subsequent election.

Table 9 shows the results of our analysis. We test for an effect of a female mayor winning a close election on the municipal vote share of all the female candidates for each office on the ballot in 2010. For each of these offices we run two models: one with a bandwidth of one percent and one with the optimal bandwidth proposed by Imbens and Kalyanaraman (2009). ${ }^{10}$ We find mixed evidence of a demonstration effect of female mayors on the vote share of female candidates in the 2010 election. Of the five offices on the ballot in 2010, only the vote shares of female candidates for state deputy are consistently and significantly impacted by the election of a female mayor in 2008. ${ }^{11}$ Perhaps most surprisingly, this effect is in the opposite of the anticipated direction - in municipalities that elected a female mayor in 2008, voters were less likely to vote for female candidates for state deputy than in municipalities which elected a male mayor. Thus, although we find evidence of a demonstration effect on this part of the 2010 ballot, it is a negative demonstration effect.

\section{TABLE 9 ABOUT HERE}

The vote share of female gubernatorial candidates are the only other part of the 2010 ballot significantly impacted by a female mayor winning office in 2008. However, this significant effect appears only at the optimal bandwidth (9.36\%) which substantively we believe

\footnotetext{
${ }^{9}$ Others have found diffusion effects from the election of women; the election of a woman in one municipality increases the probability that a woman will run in a neighboring municipality (Gilardi, 2013). We do not have the space to fully explore this hypothesis in this paper.

${ }^{10}$ For each office we ran RDD models with all bandwidths from $1-10 \%$ in $1 \%$ increments. Results for state deputy were consistent across all bandwidths. Here we include the only the $1 \%$ bandwidth.

${ }^{11}$ We exclude from our analysis municipalities in which the mayor did not complete his or her term because he/she was subsequently "cassado" - removed from office for unlawful activity.
} 
is too wide to credibly indicate assignment "as if random". For all other elections on the ballot we find no significant demonstration effect on female vote share.

There are obvious shortcomings with this test. The lack of a demonstration effect at the mayoral level may not be generalizable to the Presidential level. Mayors are important political actors, but their profile and prestige obviously do not match that of national leadership. In addition, we have not controlled for mayoral performance. President Rousseff's popularity might have reflected a combination of gender and (at the time) a strong economy. The combination of the two might lead voters to prefer women for other offices, hoping for similar high-performance outcomes. Unfortunately, we do not have comparable performance data at the municipal level. We can conclude, however, that in our sampled municipalities, that the experience of having a woman mayor had no significant impact on subsequent vote shares for women.

\section{Discussion}

In this paper we have examined the gender gap in candidate support in Brazil, with surprising results. In a survey experiment, we found evidence that both female and male voters were favorably disposed toward female candidates in São Paulo, with about a 7\% percentage point increase in support for a hypothetical candidate when that person was female instead of male. Looking at the gender bias by the race of the candidate, we found that there was no gender bias for black candidates but the bias remained among the white candidates. The core result does pose a challenge: if there is a pro-female bias, why are women underrepresented in the National Congress?

In a second round of experiments, using new software, we sought to answer this question, testing for an interaction between ballot length and gender bias. Yet when randomizing candidate gender, across different issues, ballot sizes, and backgrounds, we still found a consistent positive bias for female candidates. The size of the effect in our study was close to 
7 percentage points regardless of ballot length. The simple treatment effect was consistently significant with diverse controls, and there was little evidence that the impact of gender varied across any of the usual suspects: subjects' gender, education, political interest, age, and others.

The only variables that appeared to modestly affect the gender gap were partisanship and issue priorities. Subjects expressing support for leftist parties having a larger gender gap than those with other partisan preferences. Notably, however, there was still a pro-woman bias among subjects for all parties. There is modest evidence of a relationship between the subjects' policy priorities and gender preference - but even stronger again was the profemale bias which persists across all policy priorities. Further, neither partisanship nor issue priorities had statistically significant effects on the size of the gender bias.

Our results naturally prompted some search for explanation. At the time of the study, Brazil's first female President, Dilma Rousseff, was enjoying remarkable popularity and public support. We hypothesized that our observed positive gender bias might be the result of a demonstration effect - the projection of the support for Dilma onto other female politicians. To test this hypothesis, we exploited mayoral elections in an RDD to measure the impact of a woman winning a mayoral contest on the votes shares of other women in subsequent elections. For some subsequent elections we found no relationship and in other cases we found that the election of a woman actually reduced women's vote shares. This result might signal that for dissatisfied voters who have experience with female mayors, female politicians are no longer outsiders and so voters cannot express their frustration with the system by voting for a woman.

Our findings are remarkable and unexpected. Women have increased their political participation and power significantly over the last decades, but still face many challenges in Brazil. We expected a negative gender gap which would increase with ballot length, as voters would rely more on negative stereotypes towards female politicans. Instead, we found a remarkably strong and stable positive gender gap in all our experimental treatments. 
We see these results as a call to expand research on voters' attitudes about gender and leadership. In particular, we see pressing challenges to refine and extend our findings, as well as a proximate agenda to link our experimental results with the reality of women's underrepresentation in many areas of Brazilian politics.

Regarding the first, we are convinced of the strength and robustness of our results, but there are several potential design improvements and changes to refine and extend these results. One would be dropping the inclusion of candidate photos in the experiment, to see if some measure of pleasantness or attractiveness explains the gender gap we observed. We believe this an unlikely explanation for our results, because we varied the pictures of all the candidates, and randomly drew female and male images from a larger sample of pictures of women and men. Furthermore, we tested for picture-effects, and found no evidence, after controlling for gender and race, that candidate pictures affected vote choice. ${ }^{12}$

In addition, our design should be extended beyond urban São Paulo and internet pools to a representative sample of all Brazilians, with adequate representation of the poor and rural voters. Presumably, these cohorts would be most likely to hold traditional attitudes and might yield very different results than did our samples. At the same time, we do not expect this to change our overarching finding. The great majority of Brazilians today live in urban areas, and the rural voters are a smaller and smaller group. Further, our samples included a small number of low income subjects, and for these subjects, we observed the same pro-female bias in candidate choice.

A reviewer and several other readers have pointed out another possible explanation for the pro-female bias that we cannot test here: it may be that the consistent minority status of the female candidates in our experiment are driving the result - women were a minority of all treatments where they appeared, always $1 / 3$ of candidates. We might see different

\footnotetext{
${ }^{12}$ Specifically, we tested whether a model which included dummy variables for each candidate image fit the data significantly better than a model which only had dummy variables for race and gender. We failed to reject the null at the .05 level. This result has limitations; it tests whether there are significant differences between same race and same gender images in the study, but cannot test whether all the women candidates' images were more pleasant than, say, all the men's images.
} 
results were they a majority of the candidates. However, empirically, women are a minority of candidates in Brazil - so our experiment mirrors the gender distribution voters actually face.

Lastly, our design requires additional research into the intersection of race and gender. In our pilot study, we varied the race of our female candidates; in the follow-up we did not have the resources to do so. The pilot study suggested neither positive nor negative bias for black female candidates. The study was limited, and the finding potentially very important, and deserves replication and extension.

With respect to methodology, the fully randomized design employed by the MPH survey platform in our second experiment can be applied in future work exploring the relationship between candidate characteristics and vote choice. By allowing race, gender, and other candidate qualities to vary independently from one another, we can more accurately identify the effects of those attributes on vote choice as well as any interactions between candidate attributes and institutions.

The preceding suggest experimental work to better understand the nature of voters' attitudes. At the same, time, given our robust pro-woman finding, a new puzzle deserves attention: given voters' apparent strong preference for female candidates, why are there not more women holding office in Brazil? Indeed, there should be more women than men in office, given our results, yet women are just 10\% of Brazil's National Congress. Our experimental results suggest that this is not a problem associated with voter attitudes, ballot size, or choice set psychology.

A promising area of investigation should be in the institutions that shape candidate recruitment and resources. This implies studies of the types of candidates entering politics, and some research on why many accomplished women do not enter politics in Brazil. Further, for those who do run, are their bids as successful as men's, or less successful? Future investigations might ask whether there is bias in the allocation of campaign resources, perhaps on the part of parties through media time and prominence or through donors. 
Returning to our core findings of a pro-woman bias, we believe that, given women's historical underrepresentation in Brazilian political leadership, they may represent a class of outsiders to those unsatisfied with the political system or the goods it delivers. The protests of 2013, which continue at time of this writing, reveal a great deal of frustration with many aspects of the Brazilian political system. Nearly every politician talks of change, reform, integrity, and progress - but many Brazilians are unsatisfied with their performance. Women may represent outsiders, an alternative to a failing status quo and perhaps a new future.

If our hypothesis proves correct, this puts additional pressure on the Rousseff administration to meet expectations. Elected with substantial support as the successor to a very popular president, her administration has been challenged by slowing growth in emerging markets, continuing corruption scandals, and challenges in the approaching Olympic games. Should the Rousseff administration fail to deliver, this may be a negative example that will reduce support for women across Brazil. As Htun (2002) observes, expectations for elected women tend to be higher than those for elected men. Whether the result will be a negative gender bias remains to be seen. 
Table 1: Candidate Choice by Candidate Gender and Race in First Experiment

\begin{tabular}{lllllll} 
& \multicolumn{4}{c}{ Candidate Race: } \\
& \multicolumn{2}{c}{ Combined } & White & \multicolumn{2}{c}{ Black } \\
Candidate Race & $p$ & $n$ & $p$ & $n$ & $p$ & $n$ \\
\hline Female & 0.257 & 296 & 0.284 & 148 & 0.230 & 148 \\
Male & 0.196 & 312 & 0.181 & 160 & 0.211 & 152 \\
Difference & 0.061 & & 0.103 & & 0.019 & \\
P-value & 0.071 & & 0.033 & & 0.688 & \\
& & & & & & \\
\end{tabular}


Table 2: Candidate Choice by Ballot Length and Subject Gender

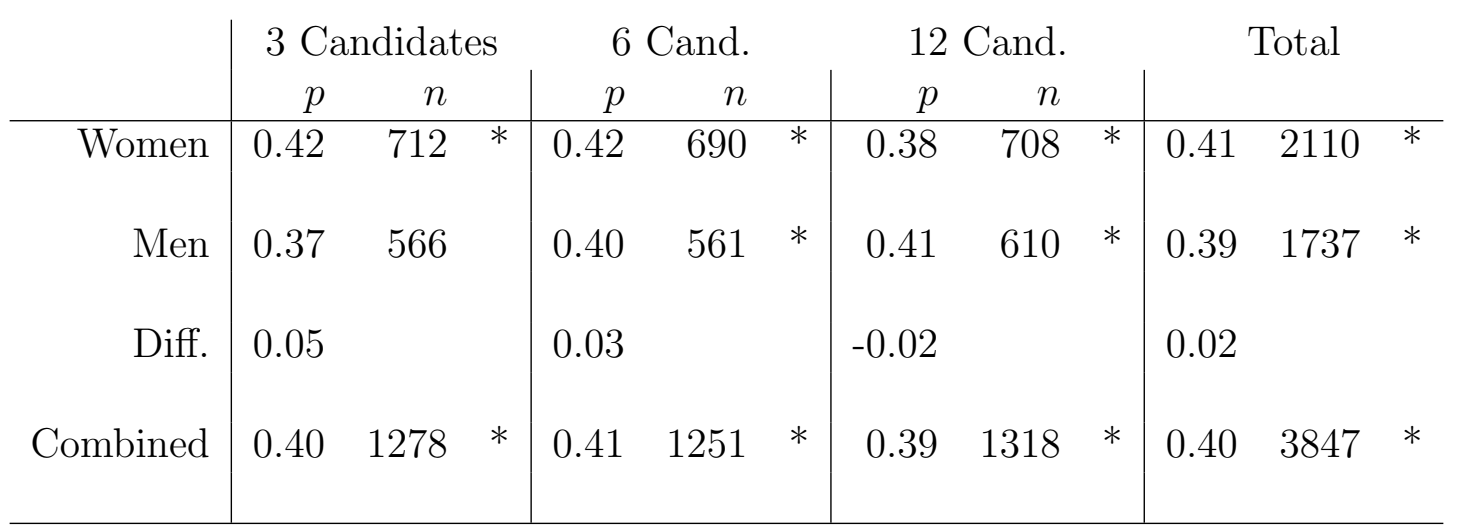

Cells report the proportion of each cohort choosing one of the women candidates, with a baseline proportion of .33 under random voting. Asterisks denote significance at the .05 level for deviations from baseline .33 voting, or for differences between men and women subjects, as labeled. 
Table 3: Vote Choice by Gender and Education

\begin{tabular}{|c|c|c|c|c|c|c|c|c|c|c|c|c|}
\hline & \multicolumn{3}{|c|}{$\mathrm{x}<\mathrm{HS}$} & \multicolumn{3}{|c|}{ HS } & \multicolumn{3}{|c|}{ College } & \multicolumn{3}{|c|}{$\mathrm{x}>$ College } \\
\hline & $p$ & $n$ & & $p$ & $n$ & & $p$ & $n$ & & & & \\
\hline Women & 0.42 & 93 & & 0.40 & 675 & $*$ & 0.42 & 672 & $*$ & 0.41 & 670 & $*$ \\
\hline Men & 0.43 & 105 & * & 0.40 & 529 & * & 0.38 & 538 & $*$ & 0.39 & 565 & $*$ \\
\hline Difference & -0.01 & & & -0.00 & & & 0.04 & & & 0.01 & & \\
\hline Combined & 0.42 & 198 & $*$ & 0.40 & 1204 & * & 0.40 & 1210 & $*$ & 0.40 & 1235 & $*$ \\
\hline
\end{tabular}

Cells report the proportion of each cohort choosing one of the women candidates, with a baseline proportion of .33 under random voting. Asterisks denote significance at the .05 level for deviations from baseline .33 voting, or for differences between men and women subjects, as labeled. 
Table 4: Vote Choice by Political Interest

\begin{tabular}{r|rrr} 
Interest & $p$ & & $n$ \\
\hline Not Interested & 0.40 & $*$ & 482 \\
Little Interested & 0.42 & $*$ & 1254 \\
Interested & 0.40 & $*$ & 1468 \\
Very Interested & 0.39 & $*$ & 645 \\
\hline
\end{tabular}

Cells report the proportion of each cohort choosing one of the women candidates, with a baseline proportion of .33 under random voting. 
Table 5: Vote Choice by Subjects' Top Issues

\begin{tabular}{r|rrr} 
& $p$ & $n$ \\
\hline Corruption & 0.39 & $*$ & 2031 \\
Crime & 0.39 & & 145 \\
Economy & 0.39 & & 144 \\
Education & 0.43 & $*$ & 669 \\
Healthcare & 0.42 & $*$ & 546 \\
Other & 0.40 & $*$ & 314
\end{tabular}

Cells report the proportion of each cohort choosing one of the women candidates, with a baseline proportion of .33 under random voting. 
Table 6: Vote Choice by Age and Gender

\begin{tabular}{|c|c|c|c|c|c|c|c|c|c|c|c|c|}
\hline \multirow[b]{2}{*}{ Age } & \multicolumn{3}{|c|}{$18-30$} & \multicolumn{3}{|c|}{$31-45$} & \multicolumn{3}{|c|}{$46-59$} & \multicolumn{3}{|c|}{$60+$} \\
\hline & $p$ & $n$ & & $p$ & $n$ & & $p$ & $n$ & & $p$ & $n$ & \\
\hline Women & 0.41 & 1029 & $*$ & 0.42 & 739 & $*$ & 0.38 & 286 & & 0.42 & 53 & \\
\hline Men & 0.37 & 577 & & 0.38 & 643 & $*$ & 0.43 & 397 & $*$ & 0.42 & 117 & \\
\hline Difference & 0.04 & & & 0.03 & & & -0.04 & & & -0.00 & & \\
\hline Combined & 0.40 & 1606 & * & 0.40 & 1382 & $*$ & 0.41 & 683 & * & 0.42 & 170 & $*$ \\
\hline
\end{tabular}

Cells report the proportion of each cohort choosing one of the women candidates, with a baseline proportion of .33 under random voting. 
Table 7: Vote Choice by Subjects' Self-Identified Partisanship

\begin{tabular}{r|rrr} 
& $p$ & & $n$ \\
\hline None & 0.40 & $*$ & 3103 \\
Other & 0.42 & $*$ & 255 \\
PSDB & 0.37 & & 164 \\
PT & 0.44 & $*$ & 251 \\
PV & 0.50 & $*$ & 76 \\
\hline
\end{tabular}

Cells report the proportion of each cohort choosing one of the women candidates, with a baseline proportion of .33 under random voting. 
Table 8: Conditional Logit Models of Vote Choice

\begin{tabular}{|c|c|c|c|}
\hline Candidate Choice & Model 1 & Model 2 & Model 3 \\
\hline Woman Candidate & $0.407^{* * *}$ & $0.406^{* * *}$ & $0.469^{* * *}$ \\
\hline & $(0.075)$ & $(0.056)$ & $(0.080)$ \\
\hline Woman Cand * Ballot Length & $\begin{array}{c}0.007 \\
(0.009)\end{array}$ & & \\
\hline \multirow[t]{2}{*}{ Nonwhite Candidate } & $0.234^{* * *}$ & $0.115^{*}$ & $0.114^{*}$ \\
\hline & $(0.043)$ & $(0.053)$ & $(0.053)$ \\
\hline \multirow[t]{2}{*}{ Woman Cand \& Subject } & & 0.092 & 0.092 \\
\hline & & $(0.068)$ & $(0.069)$ \\
\hline \multirow[t]{2}{*}{ Nonwhite Cand \& Subject } & & $0.301 * * *$ & $0.301 * * *$ \\
\hline & & $(0.072)$ & $(0.072)$ \\
\hline \multirow[t]{2}{*}{ Ballot Position } & & $-0.044^{* * *}$ & $-0.044^{* * *}$ \\
\hline & & $(0.007)$ & $(0.007)$ \\
\hline \multirow[t]{2}{*}{ Candidate Proximity to Voter } & & $-0.079^{* * *}$ & $-0.079^{* * *}$ \\
\hline & & $(0.007)$ & $(0.007)$ \\
\hline \multirow[t]{2}{*}{ Woman Cand ${ }^{*}$ Health } & & & -0.041 \\
\hline & & & $(0.109)$ \\
\hline \multirow[t]{2}{*}{ Woman Cand * Family } & & & -0.242 \\
\hline & & & $(0.173)$ \\
\hline \multirow[t]{2}{*}{ Woman Cand $*$ Corruption } & & & -0.134 \\
\hline & & & $(0.078)$ \\
\hline \multirow[t]{2}{*}{ Woman Cand * Party } & & & 0.111 \\
\hline & & & $(0.082)$ \\
\hline $\mathrm{N}$ & 25758 & 25746 & 25746 \\
\hline
\end{tabular}




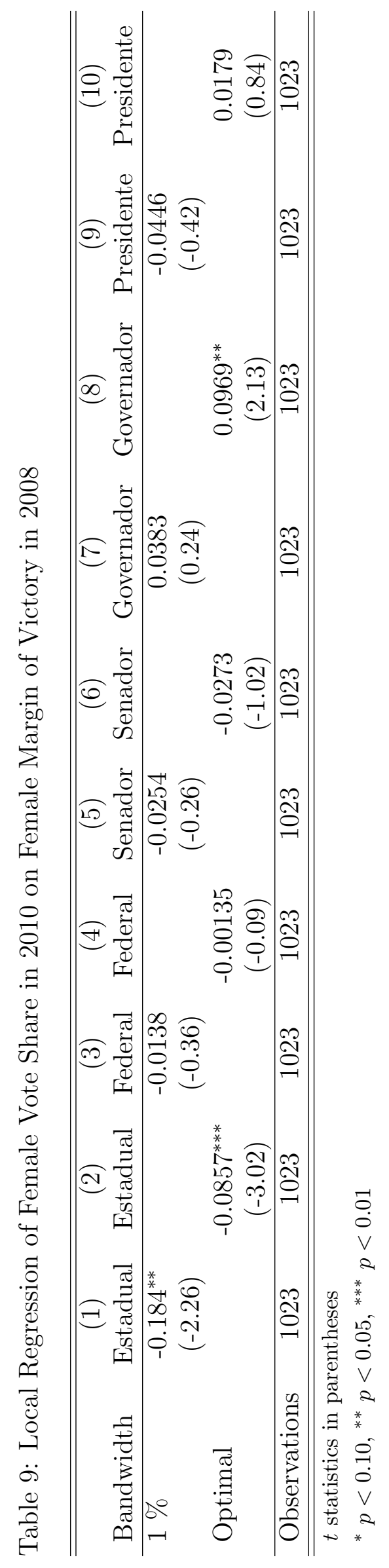


Figure 1: Candidate Profiles with "Treatment Candidate" of Varying Race and Gender (First Experiment)

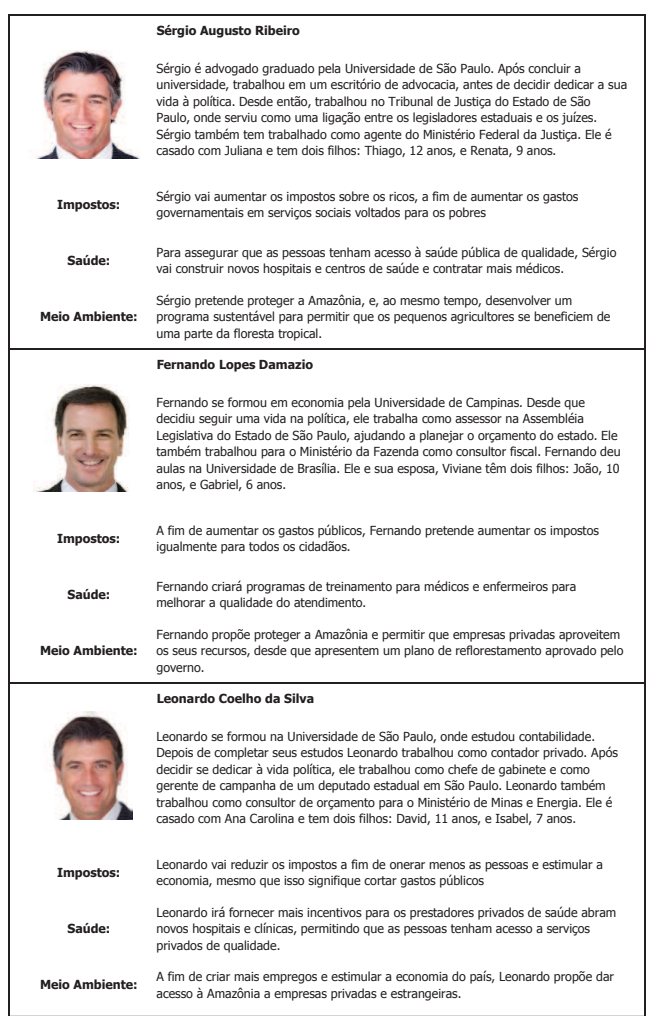

(a) White Male

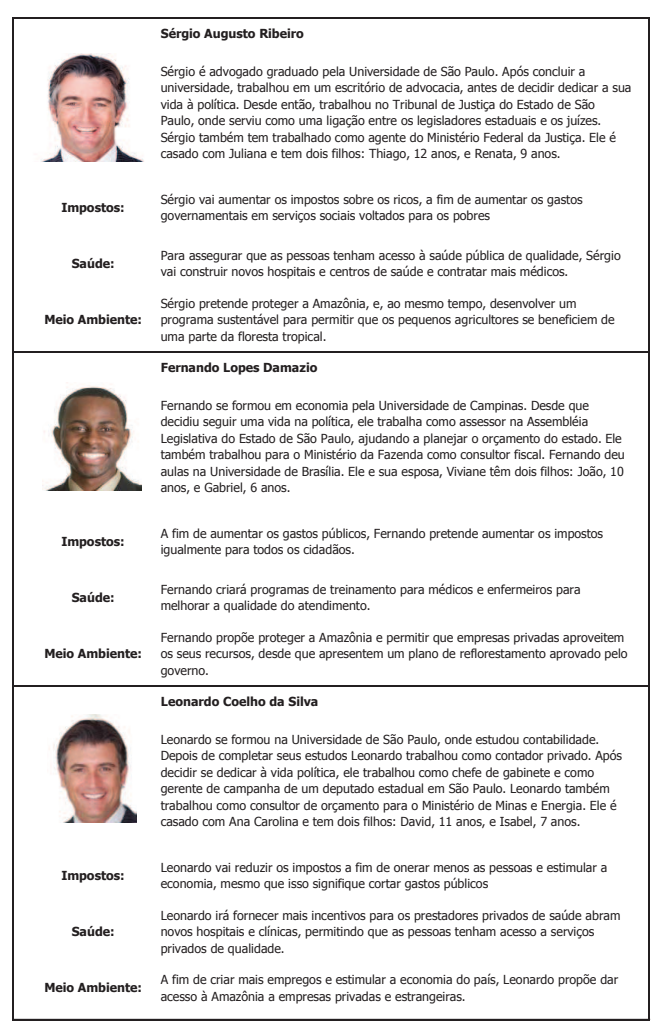

(b) Black Male

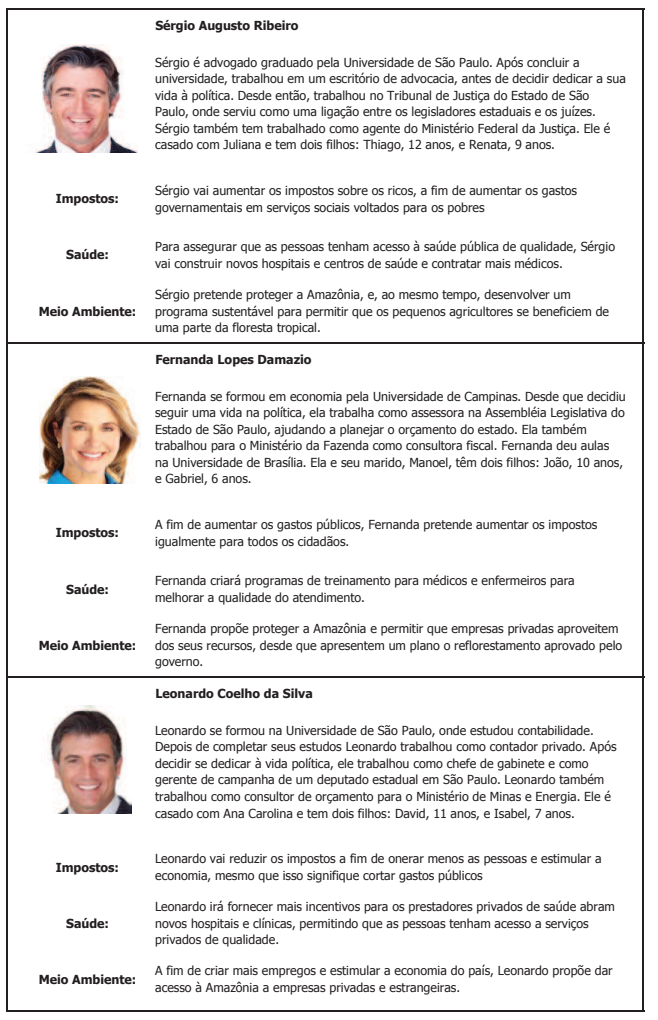

(c) White Female

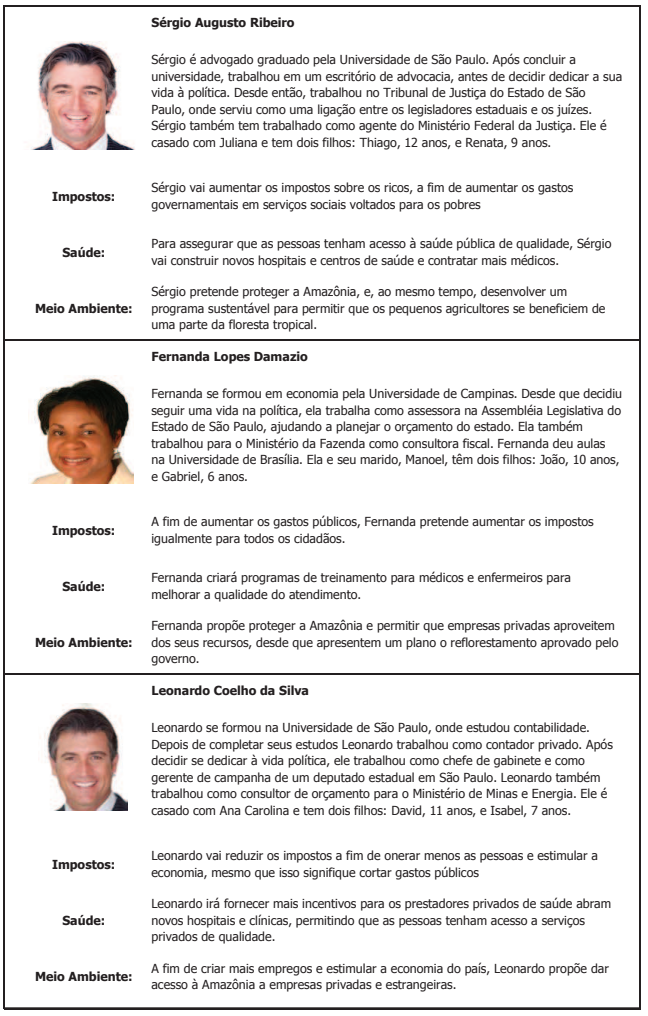

(d) Black Female 
Figure 2: Experimental Ballots Generated by MPH (with English translations)

Vitória Ribeiro
$\begin{aligned} & \text { Biographies click HERE } \\ & \text { Issues click HERE } \\ & \text { vote }\end{aligned}$

(a) 3 Candidate Ballot

Marcela Almeida
Biographies click HERE
Issues click HERE
vote
$\begin{aligned} & \text { Biographies click HERE } \\ & \text { Issues click HERE } \\ & \text { vote }\end{aligned}$

(b) 6 Candidate Ballot

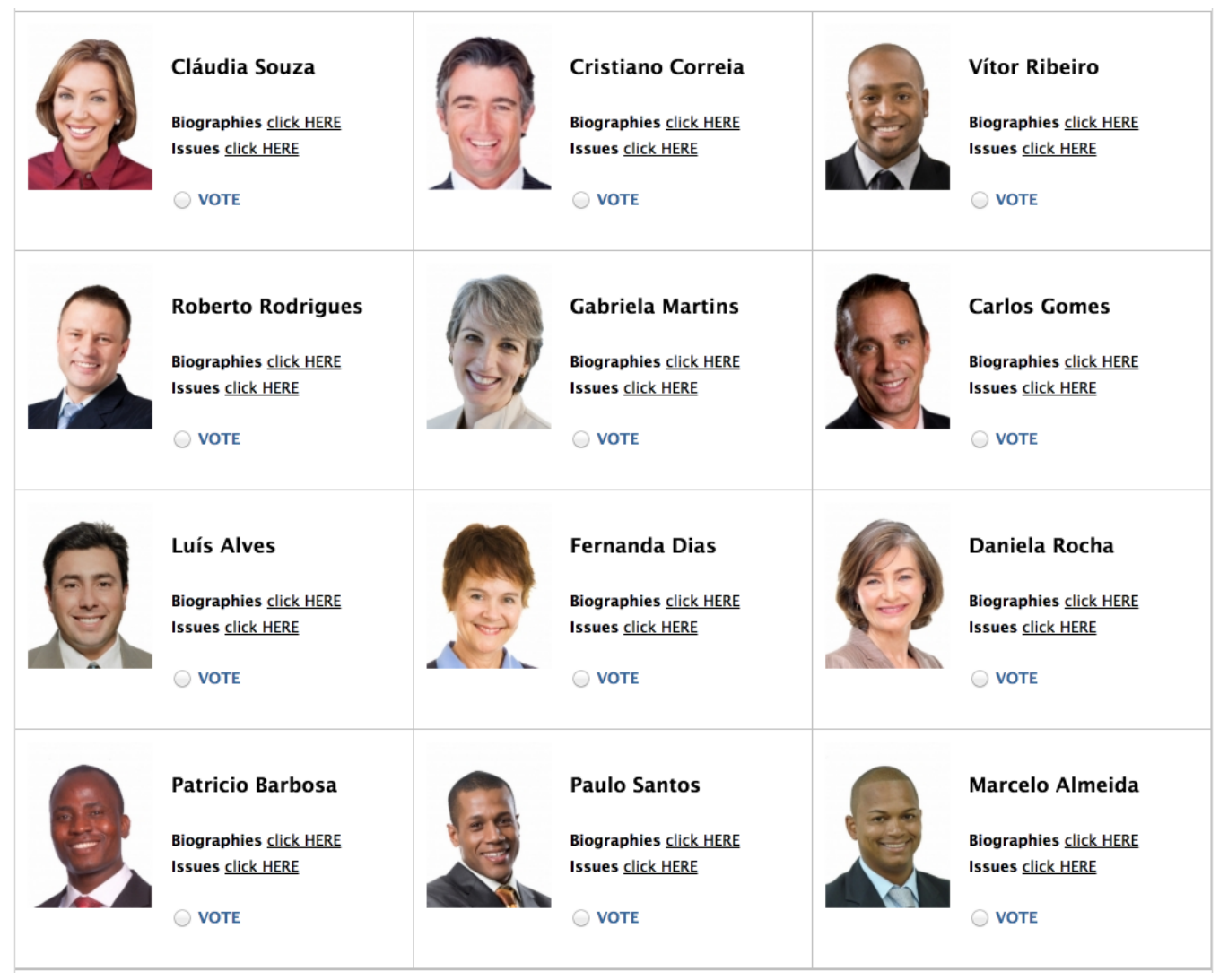

(c) 12 Candidate Ballot 


\section{Acknowledgements}

The authors thank Dr. George Avelino of the Fundação Getúlio Vargas for support and suggestions, as well as Leonardo Barone, Eduardo Sato, Jaqueline Zulini, Marina Marçola, and Juliana Bueno for terrific fieldwork and survey implementation. Valuable comments were also provided by The Brown University Political Science Department Seminar Series, the Graduate Institute of Geneva Department of Political Science, the University of Zurich's Publication Seminar, and CIDE Political Studies Division Seminar Series. Funding was provided by a UCSD Committee on Research Grant and a Doctoral Dissertation Research

Improvement Grant from the National Science Foundation (SES-1123236). Replication data will be made available on the corresponding author's website upon publication. 


\section{References}

Aguilar, Rosario, Saul Cunow, Scott Desposato and Leonardo Barone. Forthcoming. "Ballot Structure, Candidate Race, and Vote Choice in Brazil." Latin American Research Review

Alexander, Deborah and Kristi Andersen. 1993. "Gender as a factor in the attribution of leadership traits." Political Research Quarterly 46(3):527-545.

Baldez, Lisa. 2004. "Elected Bodies: The Gender Quota Law for Legislative Candidates in Mexico." Legislative Studies Quarterly 29:231-258. 2.

Burrell, Barbara C. 1995. A Woman's Place is in the House: Campaigning for Congress in the Feminist Era. University of Michigan Press.

Cunow, Saul. 2014. "More is Less (Representation): Choice Set Size, Information Acquisition, and Correct Voting in Multimember Districts." Paper Presented at the Montreal Voting Experiment Workshop, University of Montreal, March 28-29, 2014.

Dolan, Kathleen. 1997. "Gender Differences in Support for Women Candidates." Women $\&$ Politics 17:27-41. 2.

Dolan, Kathleen. 2010. "The Impact of Gender Stereotyped Evaluations on Support for Women Candidates." Political Behavior 32:69-88. 1.

Flannelly, Kevin J. 2002. "Voting for female candidates: Effects of voters' age, ethnicity, and gender." The Journal of social psychology 142(3):397-399.

Franceschet, Susan, Mona Lena Krook and Jennifer M. Piscopo. 2012. The Impact of Quotas on Women's Descriptive, Substantive, and Symbolic Representation. Oxford: Oxford University Press.

Gilardi, Fabrizio. 2013. "The temporary importance of role models for women's political representation." Paper presented at the annual meeting of the APSA, 2013. 
Hainmueller, Jens, Daniel J. Hopkins and Teppei Yamamoto. 2014. "Causal Inference in Conjoint Analysis: Understanding Multidimensional Choices via Stated Preference Experiments." Political Analysis 22(1):1-30.

Htun, Mala. 2002. "Puzzles of Women's Rights in Brazil." Social Research 69(3):733-751.

Htun, Mala N. and Mark P. Jones. 2002. Engendering the Right to Participate in Decisionmaking: Electoral Quotas and Women's Leadership in Latin America. In Gender and the Politics of Rights and Democracy in Latin America, ed. Nikki Craske and Maxine Molyneux. New York: Palgrave pp. 32-56.

Huddy, Leonie and Nayda Terkildsen. 1993. "The Consequences of Gender Stereotypes for Women Candidates at Different Levels and Types of Office." Political Research Quarterly 46:503-525. 3.

Imbens, Guido and Karthik Kalyanaraman. 2009. Optimal Bandwidth Choice for the Regression Discontinuity Estimator. Working Paper 14726 National Bureau of Economic Research.

URL: http://www.nber.org/papers/w14726

Inglehart, Ronald and Pippa Norris. 2003. Rising tide: Gender equality and cultural change around the world. Cambridge University Press.

IPEA. 2014. "Tolerância social à violência contra as mulheres.".

URL: http://www.ipea.gov.br/portal/images/stories/PDFs/SIPS/140327_sips_violencia_mulheres.pdf

IPU, Inter-Parliamentary Union. 2014. "Women in National Parliaments, World Situation.".

Jones, Mark P. 1996. "Increasing Women's Representation via Gender Quotas: The Argentine Ley de Cupos." Women 63 Politics 16:75-96.

Jones, Mark P. 1998. "Gender Quotas, Electoral Laws, and the Election of Women." Comparative Political Studies 31:3-21. 
Jones, Mark P. 2004. "Quota Legislation and the Election of Women: Learning from the Costa Rican Experience." Journal of Politics 66:1203-1223.

Jones, Mark P. 2009. "Gender Quotas, Electoral Laws, and the Election of Women: Evidence from the Latin America Vanguard." Comparative Political Studies 42:56-81. 1.

Jones, Mark P. and Patricio Navia. 1999. "Assessing the Effectiveness of Gender Quotas in Open-list Proportional Representation Electoral Systems." Social Science Quarterly $80: 341-355$.

Kahn, Kim Fridkin and Kim Fridkin. 1996. The political consequences of being a woman: How stereotypes influence the conduct and consequences of political campaigns. Columbia University Press.

Koch, Jeffrey W. 1999. "Candidate gender and assessments of senate candidates." Social Science Quarterly 80(1):84-96.

Lammers, Joris, Ernestine H. Gordijn and Sabine Otten. 2009. "Iron ladies, men of steel: The effects of gender stereotyping on the perception of male and female candidates are moderated by prototypicality." European Journal of Social Psychology 39:186-195. 2.

Lawless, Jennifer L. 2004. "Women, war, and winning elections: Gender stereotyping in the post-September 11th era." Political Research Quarterly 57(3):479-490.

McElroy, Gail and Michael Marsh. 2010. "Candidate Gender and Voter Choice: Analysis from a Multimember Preferential Voting System." Political Research Quarterly 63:822833. 4 .

Morgan, Jana and Melissa Buice. 2013. "Latin American Attitudes toward Women in Politics: The Influence of Elite Cues, Female Advancement, and Individual Characteristics." American Political Science Review 107(04):644-662. 
Philpot, Tasha S. and H. Walton Jr. 2007. "One of Our Own: Black Female Candidates and the Voters Who Support Them." American Journal of Political Science 51:49-62.

Sanbonmatsu, Kira. 2002. "Gender Stereotypes and Vote Choice." American Journal of Political Science 46:20-34. 1.

Schmidt, Gregory D. and Kyle L. Saunders. 2004. "Effective Quotas, Relative Party Magnitude, and the Success of Female Candidates: Peruvian Municipal Elections in Comparative Perspective." Comparative Political Studies 37:704-724.

Schwindt-Bayer, Leslie A., Michael Malecki and Brian F. Crisp. 2010. "Candidate Gender and Electoral Success in Single Transferable Vote Systems." British Journal of Political Science 40(03):693-709.

Terkildsen, Nayda. 1993. "When White Voters Evaluate Black Candidates: The Processing Implications of Candidate Skin Color, Prejudice, and Self-Monitoring." American Journal of Political Science 37:1032-1053. 